\title{
DOCUMENTATION AND ANALYSIS OF THE CURRENT HOUSING TRENDS IN MACHAR COLONY IN KARACHI, PAKISTAN
}

\author{
Mansoor Raza*
}

\begin{abstract}
The population growth rate of Karachi is way beyond average national growth rate. Keeping aside the reasons for this extravagant growth, the phenomenon puts high demand on all aspects of civic life, and housing is no exception. The supply for housing for poor is not coming from formal sectors, which results in the creation of squatter settlements. Some of the theorists view these squatters as an indicator of poor's desire for self improvement. The informality in Karachi is tacitly promoted by state institutions to value-tag land for future formal commercial enterprises. The resulting uncertainty is an impediment to the freedom of poor and hence human development.
\end{abstract}

This paper documents and analyses the land use of Karachi, from the perspective of housing in an informal settlement, by taking Machar Colony as a case study. Literature review, stakeholders' interviews, on-site observations and pictorial documentation are the prime characteristics of the research methodology.

Keyword: Informality, housing, fear, freedom, commodification, Karachi, Machar Colony

\section{INTRODUCTION}

\section{Reasons for Choosing Machar Colony}

The reasons for selecting Machar Colony as a case study are as follows:

a) Machar Colony is the largest katchi abadi (informal settlement) of Karachi with an estimated population between 700,000 to 1.2 million.

b) It is one of the oldest katchi abadi of Karachi as well and over the years several distinct communities (from rituals, culture and language, attire and dietary habits perspective) have established themselves in the area.

c) The area is abode to migrant population. The Karachi Fisheries Harbour is a centripetal and binding force for majority of the residents living in Machar Colony for livelihood opportunities.

d) Despite being an old settlement, Machar Colony's land use and housing is still evolving. It is expanding, going through densification and consolidation and has a distinctive demographic characteristic of the inhabiting population. These aspects are discussed in detail in this paper.

Moreover, in 2016-17, the author of this study used to visit Machar Colony for another research entitled "Drivers of climate change vulnerability at different scales in Karachi', as a Senior Research Team Member, funded by International Institute of Environment and Development and supervised by Urban Planner and Architect Mr. Arif Hasan. The previous experience of the area, knowing the gatekeepers and earlier held notions about various socio-economic issues came to an advantage for the researcher, in enhanced understanding of the dynamics of housing for this study.

\section{Area Location, History and Demography}

Machar Colony or M achera (Fishermen) Colony, located in district South of Karachi in Kemari Town, has a spread of three hundred fifty two acres with approximately 88.6 acres encroached upon mangroves forests towards the sea (area calculated by the author using google map). Machar Colony has an elevation of two metres with the railway track of Wazir Mansion bordering its north eastern side. It is home to dwindling mangrove forests, and the Arabian Sea lies on its south side. The entitlement of the land of Machar Colony is with Karachi Port Trust (KPT) (Figures 1-5).

* Mansoor Raza, Lecturer, Department of Architectrue and Planning, NED University of Engineering and Technology, Karachi. Email Correspondance: mansooraza@gmail.com 


\section{LAYOUT PLAN OF KEAMARI TOWN KARACHI CITY DISTRICT}

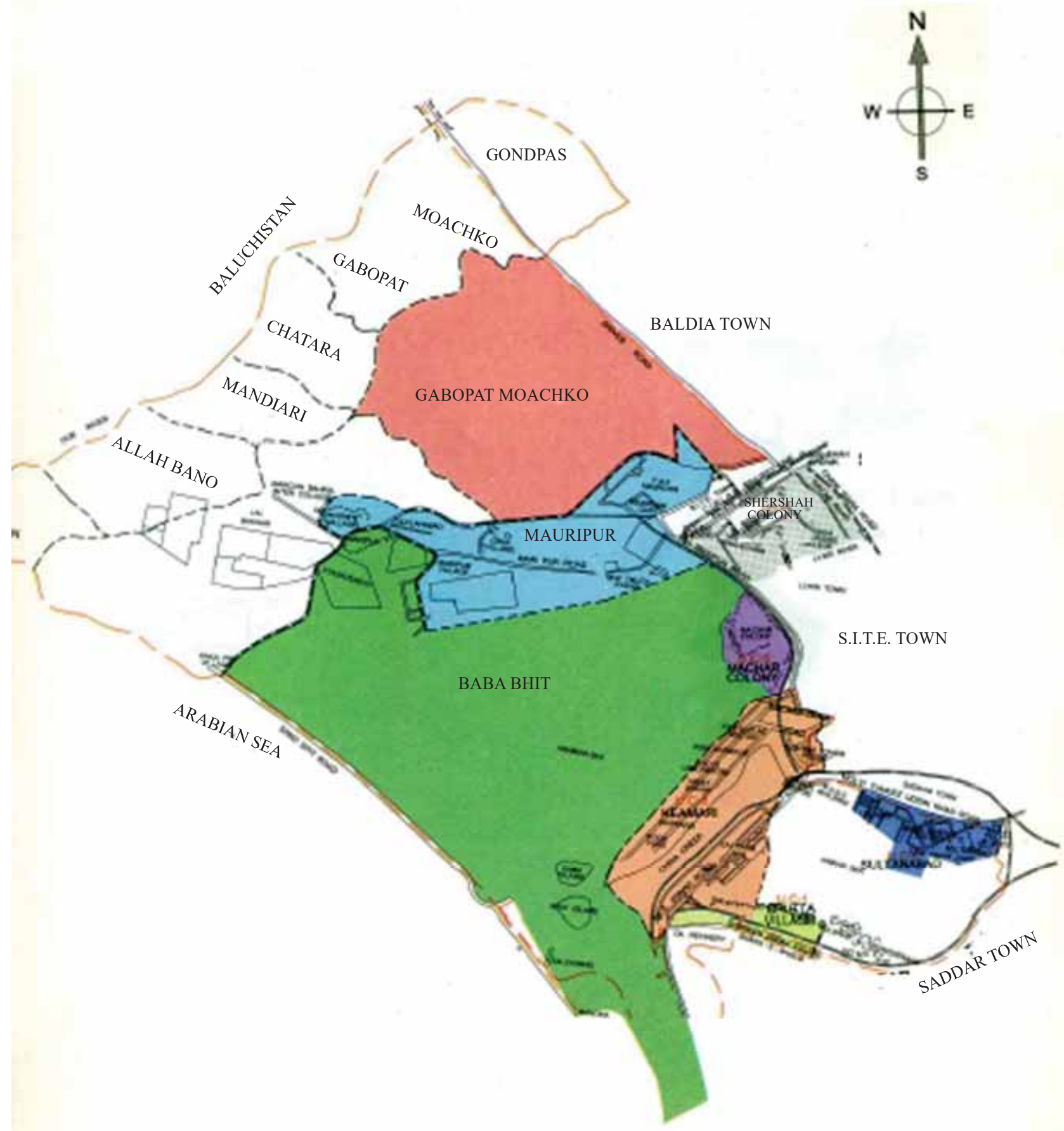

Figures 1: Location Map of Machar Colony 


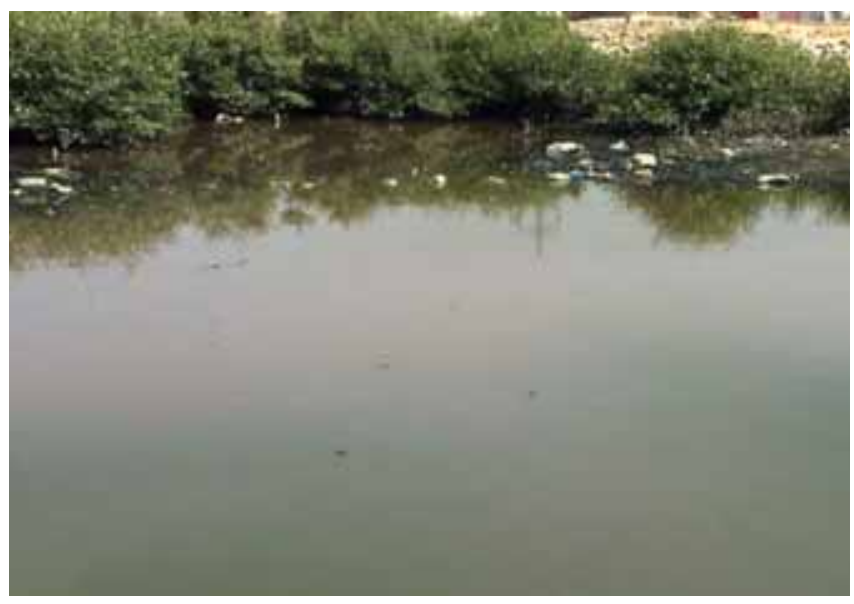

Figures 2: Mangrove Forest Area

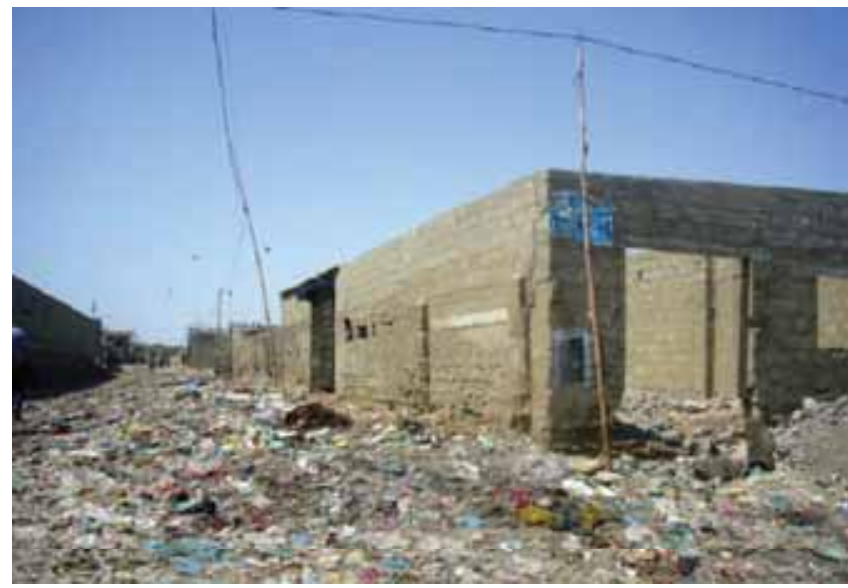

Figures 4:Typical Street in an area under development

Back in the mid sixties around ten to twelve Pashtun households migrated from Northern part of the country (Swat) to the land now known as Machar Colony to earn livelihood from Karachi Port as unskilled labourers. Bengalis came after 1970, followed by Swatis, Mianwalis, Punjabis and Sindhis. These communities prefered Machar Colony as their area of residence because of its proximity to the Karachi Fish Harbour, which is a centre for low skilled job provision. In the seventies Mr. Zulfiqar Ali Bhutto (Prime Minister of Pakistan, 1972-1977) provided electricity connection to the area.

Figure 6 gives a rough chronological development of Machar Colony. It was then, under the patronage of government officials, that the land patronization started. Though Machar Colony is the biggest and oldest settlement of Karachi, its land entitlement is yet to be regulated. Media and research reports cite various figures about the population of Machar Colony and the bandwidth of the quoted figures is from 700,000 persons to 1.2 million (The News, 2006).

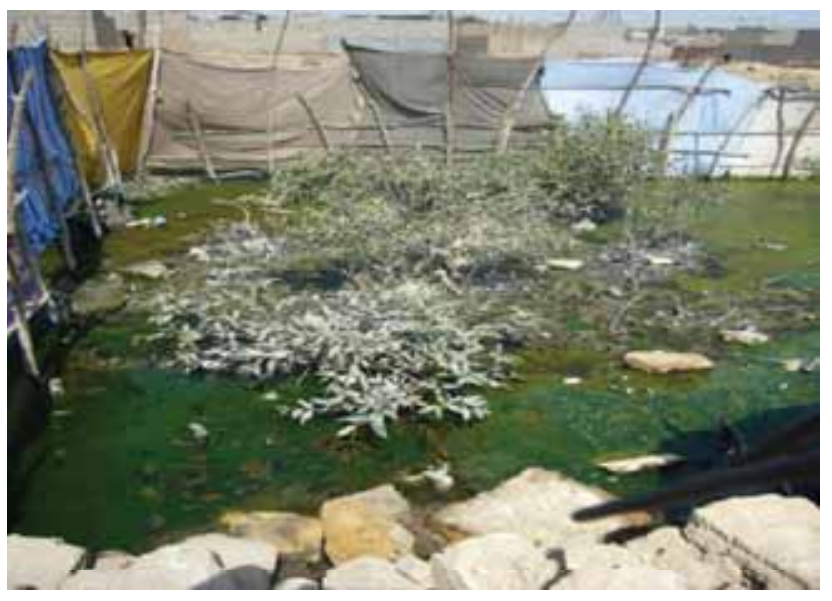

Figures 3:Demarcation of Houses in new location

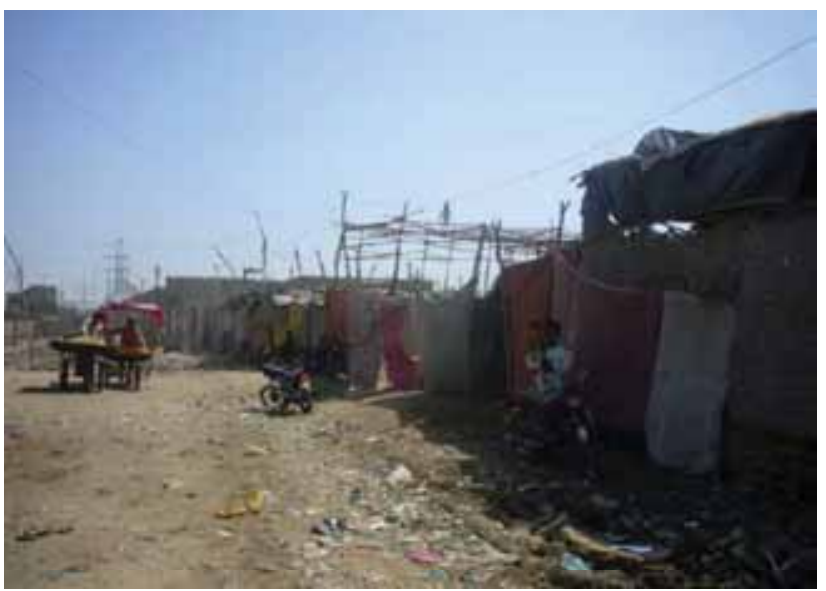

Figures 5:Typical Street of a newly developed area

Currently the locality is experiencing both horizontal and vertical expansion and has densified over the years. The apparent reason for densification is the desire by different ethnic groups to live within the respective clan based neighbourhoods. The construction for new houses is happening more towards the sea.

The Bengali and Burmese population residing in the area are involved in shrimp and fish cleaning and packing and allied businesses of ice slabs, net making and net repairing. To handle the low incomes in off seasons some households have opened up small scale grocery shops in their homes. The landscape is marked with plenty of C hai khanas (road side tea shops) mostly run by men of Pashtun ethnicity. Rickshaws, motorbikes and chingqis are the most used modes of transport. Most of the residents of the locality are employed in fisheries so walking to the place of livelihood is preferred. 


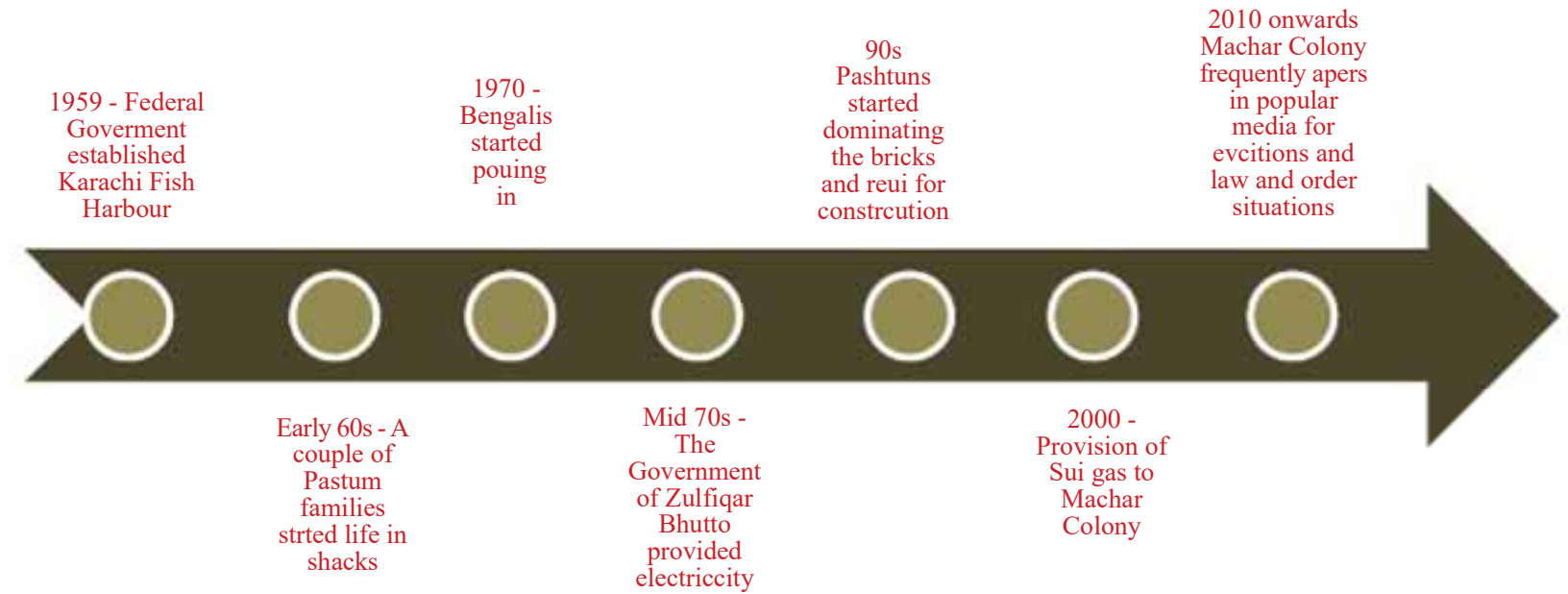

Figures 6: Chronological Development of Machar Colony

Conservative and educated guess estimates are made to establish linkages of ethnicity and professions and are summarized in Figure 7.

\section{Research Questions}

The focus of the current study was to understand how the community obtains land and build houses in Machar Colony. The objective was to document the housing process and the challenges faced, while understanding the broader socioeconomic context of the residents.

Some of the querries addressed were:

a) What factors converge to shape up community choice of making Machar Colony as choice of residence?

b) Who are the actors (formal and informal) involved in the process of obtaining land and making houses and the typology of interactions?

c) And once the shelter is secured, what are the challenges of living in Machar Colony and how do communities navigate through those?

\section{Research Methodology}

The research methodology for the study was set in accordance with the above-stated research objectives. A case study method approach was adopted for the simple reason that it is a method intensive approach and brings forth many dimensions of an issue in a shorter span of time. Secondary sources were consulted for informal housing and theories related to the phenomenon were reviewed. Media articles, as published in English dailies and YouTube videos, were reviewed to figure out the popular press perception of issues and causes of the issues related to Machar Colony. Those journalistic pieces were triangulated in the field. For this study, eleven in-depth qualitative interviews spreading a little over twenty hours, from January 24 to March 08 2018, were conducted, in the field. Snow ball sampling method was applied for the identification of key informants.

It is important to mention that to fill the gaps of the conducted primary research; the author has resorted to two other major sources of information on which the author had worked on in year 2016. One was the study on local impact of global climatic changes for International Institute of Environment and Development (IIED). Machar Colony was one of the localities selected for IIED funded research and the author was a senior team member of that particular research venture (Please visit http://pubs.iied.org/10805IIED). Second is a socio-economic survey conducted by an NGO in 2016 (Imkaan - working on civic issues of Machar Colony) which was analysed by the author. These two studies enhanced understanding of the dynamics of the area. 


\begin{tabular}{|l|l|l|}
\hline S.No & Ethniccity/Community & \multicolumn{1}{|c|}{ Occupuaion/Profession } \\
\hline 1 & Mianwali & Roaming vendors of fish and shrimps \\
\hline 2 & Bengalis & Fish and shrimp cleaning, workers at fisheries and businessmen (Fishing related) \\
\hline 3 & Pashtuns & Thallewallas and businessmen (Fishing related) \\
\hline 4 & Punjabis & Transporters and laboures \\
\hline 5 & Sindhis & Transporters and clraring and forwarding agents \\
\hline 6 & Katchis & Construction workers, masons, labourers and shuttering experts \\
\hline 7 & Burmese & Fish and shrimp cleaning and workers at fisheries \\
\hline 8 & Baloch & Sailors, mostly \\
\hline 9 & Afghanis & Transporters, dumper drivers and debris providers \\
\hline
\end{tabular}

Figures 7: The Ethnic Groups and their Professional Affiliations

Source: Based on various interviews conducted by the author between 2016-2018

\section{Research Challenges}

Like most of the researches, the study had its limitations with some associated challenges. Majority of the respondents were available after office timings and many of the probable respondents declined to meet on Sundays, for obvious reasons. At the time of this study rumors were strife about the possible land use changes and change (apparently forcible) of hands of the some parts of Machar Colony. Some of the respondents mentioned that land will go the Malik Riaz of Bahria Town with incumbents acting as conduit. A couple of others mentioned that Karachi Port Trust (KPT) will build infrastructural facilities for the China Pakistan Economic Corridor (CPEC). As a result any question about land entitlement and sale procedure were met with skepticism by the community members. In some instances the researcher braved aggression of young community members. No one from KPT was willing to talk on the subject; hence official view point could not be accommodated in this study.

\section{Structure of the paper}

The study is an attempt to understand and place the housing dynamics of Machar Colony in the socio-economic context of the area. The guiding framework for investigation in the field was that housing is more than mortar and bricks and what meets the eyes. This premise not only set the direction for the exploration, it also defined the format of the report as well. The first section introduces the objectives of the research, the ways to meet the objectives and the difficulties associated with the opted path of investigation. Section two is a brief of what is written about informal housing internationally and locally. Section three narrates the primary findings from Machar Colony and convergence towards the housing dynamics. Sections four and five are conclusions and recommendations for further studies and probable models of housing.

\section{Literature Review}

As mentioned by Zárate, 2016 and other authors, lack of services is the key feature of an informal settlement and Machar Colony is no exception to that. According to UNHabitat, 2015 at least one third of the global urban population suffers from inadequate living conditions. Lack of access to basic services like drinking water and/or sanitation, not to mention energy, waste recollection, and transportation, low structural quality of shelters, overcrowding, dangerous locations and insecure tenure are the main characteristics normally included in the definitions of so-called informal settlements (Zárate, 2016).

The debates about informal housing swing between two extreme positions of Neo-Liberal and Neo-Marxist approaches to housing Neo-Liberals emphasize on its use value whereas Neo-Marxist point towards the commodification of housing (Omenya, 2007). Neo-Marxists criticism is both in terms of social struggle in reproduction (place of residence) and in relation to production (work place). Social struggle in reproduction is best exemplified in class stratified housing for the poor living in slums and squatter settlements (Omenya, 2007). 
This is still largely relevant to Pakistan where ethnicity and class-based segregation determines reproduction and production.

Oscar Lewis is of the opinion that urban poor has a fatalistic tendency of being contended with their living conditions and this has a bearing on their housing as well: incapacity to self-initiate and sustain decent living conditions (Fegue, 2007). Lewis was opposed by Charles Abram, who articulated his experiences with Third Word Countries (TWCs) by maintaining that 'shanty towns', 'bidonvilles' and 'favelas' are not the epicenter of urban ills. In fact they are a rational step on the path of self-improvement (Fegue, 2007). Taking Abraham's iconoclastic proposition further, John Turner declared tenure security as a prerequisite in facilitating poor's commitment to the progressive transformation of their respective shelter (Fegue, 2007). William Mangin flagged the necessity for creating access to social infrastructure in squatter settlements, as unplanned physical environment remains an obstacle to access or enjoy social benefits (Fegue, 2007). Amrita Sen correlated freedom with development: defining substance of freedom as 'general capability of a person or people to live more freely'. Sen appears to be supportive (in an indirect manner) to the notions of development for informal settlements as put forward by Abram Turner and Mangin through his concepts of capacity building for urban poor (Fegue, 2007). Quoting Hernando De Soto, Ananya Roy termed the Hernando framework as heroic. As mentioned and interpreted by Roy, Soto in his book "The Other Path" (1989), wrote that an informal economy is the people's spontaneous and creative response to the state's incapacity to satisfy the basic needs of the impoverished masses (Roy, 2005).

Ahmed (2016) explains that Marxist theorist correlates informal development with capitalist driven processes of urbanisation and globalisation, linking these to Neo-Liberal and capitalist development policies. As per Ahmed this highlights how capitalist development creates spaces of injustice in which the urban poor are excluded socially and spatially from the benefits of urban life (Ahmed, 2016).

In Pakistan, in cities like Karachi, Lahore, Quetta and Faisalabad, there is a considerable increase in the number of katchi abadi. There is a backlog of about 6.2 million houses in the country with an incremental demand of about 0.25 million units per year (Siddiqui, 2015) fifty per cent of the families live in one-room tenements, their family members ranging between eight to fifteen (Siddiqui, 2015). Urban centers are growing at a rate of nearly five per cent as against the national growth rate of 2.7 per cent (Siddiqui,
2015). Both rural and urban areas are badly deficient in basic infrastructure

Low income group constitutes sixty eight percent of Karachi's population (Siddiqui, 2015). The average population density is six thousand persons per square kilometer (Siddiqui, 2015). Between 1998 and 2011, average house hold size has increased from 6.7 percent to 7.3 percent (Siddiqui, 2015). This is due to the shortage of housing and not because of any increase in fertility rates. Eighty eight percent of the houses are built on One hundred twenty and less square yards (Hasan, 2011). Houses built on four hundred to eight hundred square yards are two percent of the total houses and they occupy twenty one percent of the total thirty six percent of the residential land of Karachi (Hasan, 2011).

According to Hasan (2017) Machar Colony covers about four and a half square kilometres with a density which is four to seven times higher than the average for Karachi. In his view the congested settlement is not planned properly is under serviced and yet continues to expand. Unofficial and haphazard land reclamation that involves informal developers and som community members (mostly migrants), through dumping solid waste takes place unchecked, is large parts of the settlement are situated on what used to be mangrove forest and marshland, hence subsidence is an issue (Hasan, 2017).

\section{PRIMARY FINDINGS}

\section{Methods to Obtain Land for Construction}

Land in Machar Colony is reclaimed by first marking the boundaries by wires and bamboos and then clearing mangroves and dumping construction waste and debris. Respondents mentioned that an area in marshes covering two hundred square yards costs three hundred thousand Pakistani Rupees. A dumper of waste costs four thousand Pakistani Rupees and a two hundred and forty square yards plot needs seven to ten dumpers for filling.

Once the land is reclaimed and entitled, the sale and purchase of lot or house continues as per the local business norms, except that most of the dealings are bilateral and the involvement of a middle man or real estate agent is minimal. A stamp paper, father's or neighbour's Computerized National Identity Card (CNIC) and Karachi Electric (KE) meter number is required for sale or purchase of land. Earlier there was less sale and purchase of land and more of grabbing. Now since almost all the land is grabbed except the area towards mangrove bushes) so more sale and purchase business is prevalent. 


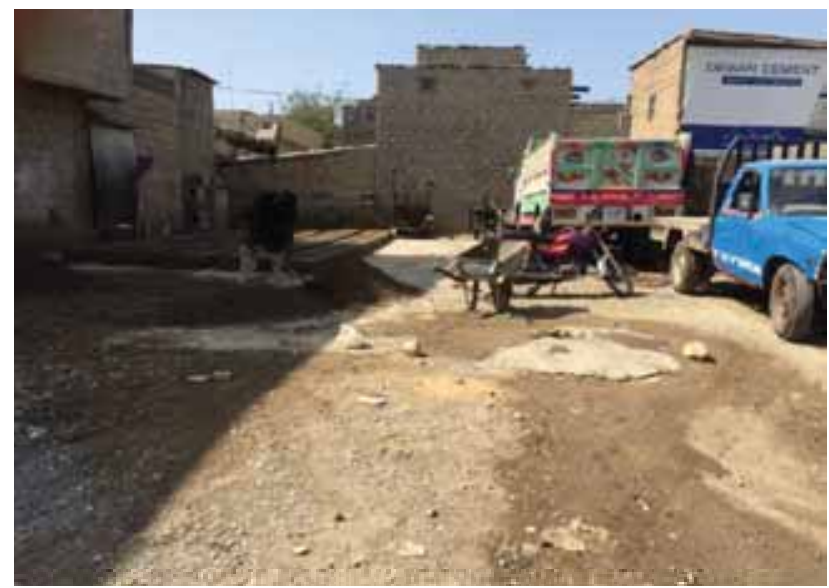

Figures 8: Thallewala courtyard at Machar Colony

\section{Role of Thallewalla (block-makers)}

It is estimated that the number of thallewallas operative in Machar Colony are around sixty and they are mostly Pashto speaking people. Cash and blocks-on-credit are the two mechanisms of transactions. The repayment time varies but four months is the average time period and the repayment is done monthly. Almost all agreements are verbal and a khata (register) is maintained by the lender. On an average seven hundred blocks are required to make one room. Those who have more money at their disposal prefer to use four inch block, otherwise three and half inches block is more popular. Four inches blocks are used mostly in pillars. Bengalis prefer three and half inches blocks more than four inch block. The cost of one block is sixteen Pakistani Rupees. One cement bag costs five hundred Pakistani Rupees and three donkey carts of gravel can make one hundred and ten to one hundred and thirty blocks. A thallewalla can provide mason and, if required can act as an architect as well (Figures 8-10).

Because of security concerns tenants are required to have a guarantor who is responsible to the landlord if any breach of agreement takes place. At times, thallewala act as a guarantor for the would-be-tenant, as he knows everybody and also the people of the locality know him. He is also the fulcrum for all construction purposes, as after obtaining a plot one has to be at good terms with him for the construction of the house. The social network is also advantageous to him as well as to the potential landlords and tenants in the offing.

Over the years the institution of the thallewalla has also transformed. Earlier the blocks were made manually and now this system is mechanized. The mode of transportation

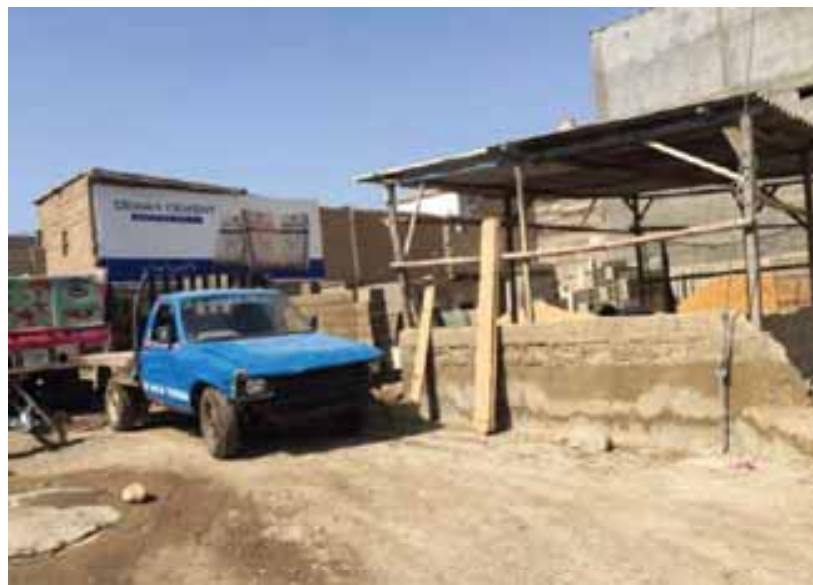

Figures 9: Thallewala yard at Machar Colony

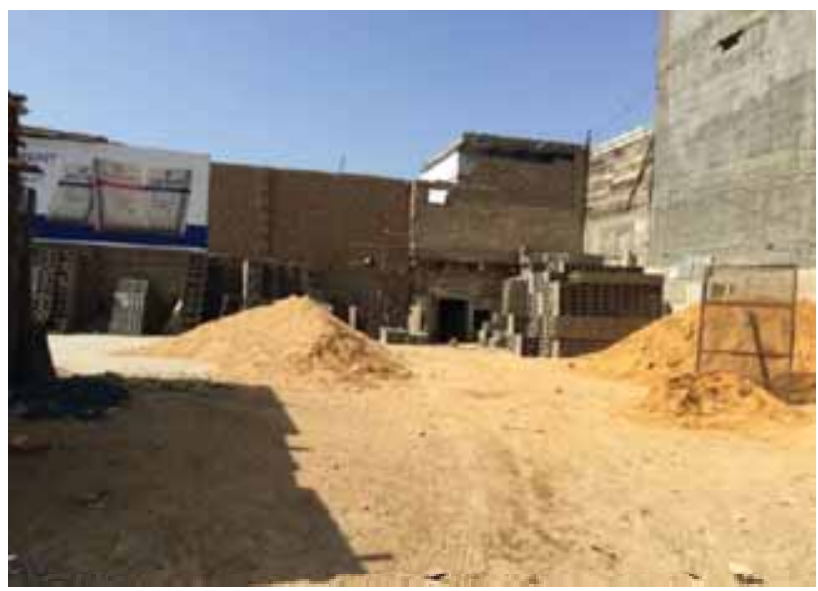

Figures 10: Another construction yard at Machar Colony

of block has also gone through changes, as earlier the blocks were transferred on donkey carts and now they are transported via mechanized modes.

\section{Construction and the Changes Over the Years}

Pacca (RCC roof tops) houses are more in vogue now. Earlier the houses were made of mud, bamboos and plastic sheets. Manually mixing is time consuming and with the advent of motor operated mixture machine per day production of blocks could is enhanced and hence the daily sales. Similarly, to transport the blocks on donkey is time consuming and numbers with limited transportation capacity whereas if Suzuki pick up is available with those thallewallas they are able to transport more blocks in less time.

With the community getting more educated and style conscious, the houses are getting fancier in their outlook. Previously, the washrooms were simple, made of cement and mortar but now most of the people want tiles. 


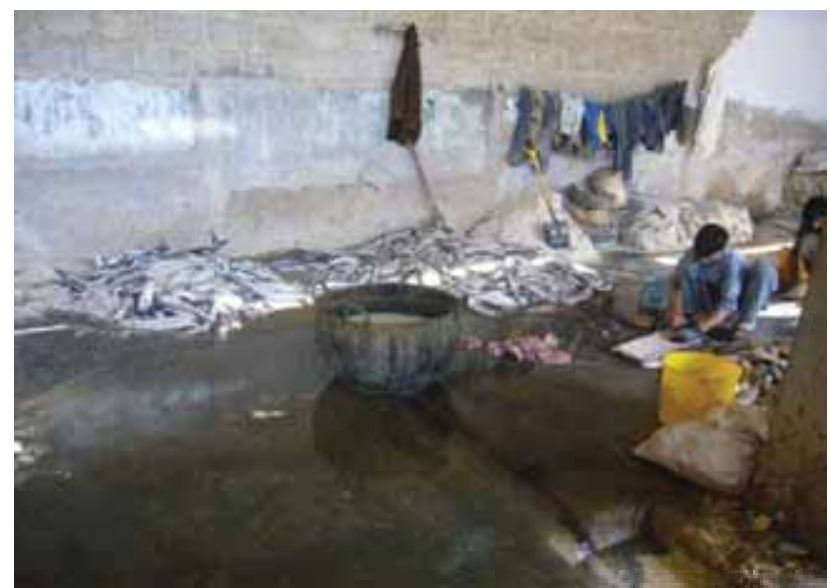

Figures 11: Interior of a Jheenga wara

Earlier, the construction of the house was a community venture and hence there was on associated feeling of ownership. The owner before starting the construction used to serve the neighborhood with a daig (large bowl for cooking) of biryani (cooked spicy rice mixed with meat) and labour for construction was provided by the community. With the advent of education and accompanying individualistic culture, this practice has changed and now the labour is hired on daily wages.

There is no standard design for a house, as they are purpose built and incremental. Streets are encroached, staircases are extended and protruding chajjas could be observed in the street. To save space and cost, earlier built houses had common walls on which the roofs of the adjourning houses rested. But with the growing demand of privacy this practice is now discontinued. Since Bengalis are a less privileged community, construction and façade of their houses do not exhibit opulence and are less showy, as compared to houses owned by Pashtuns and Balochs of the area.

\section{The Gender Grant}

The role of women in the house construction has enhanced over the years. Earlier the making of house was an entirely male rather masculine issue. Two factors are pivotal for the increasing say of women in making of a shelter. One is enhanced education of women of the area and an accompanied desire to demonstrate 'taste' in the built environment, and more importantly enhanced role as an income-generating partner. Women mostly are employed in 'jheenga bara', in which they are supposed to peel the jheengas (shrimps) for further processing (Figure 11). Each women gets twenty Pakistani Rupees to peel one small bucket of 'jheenga'. A portion of the daily income is saved

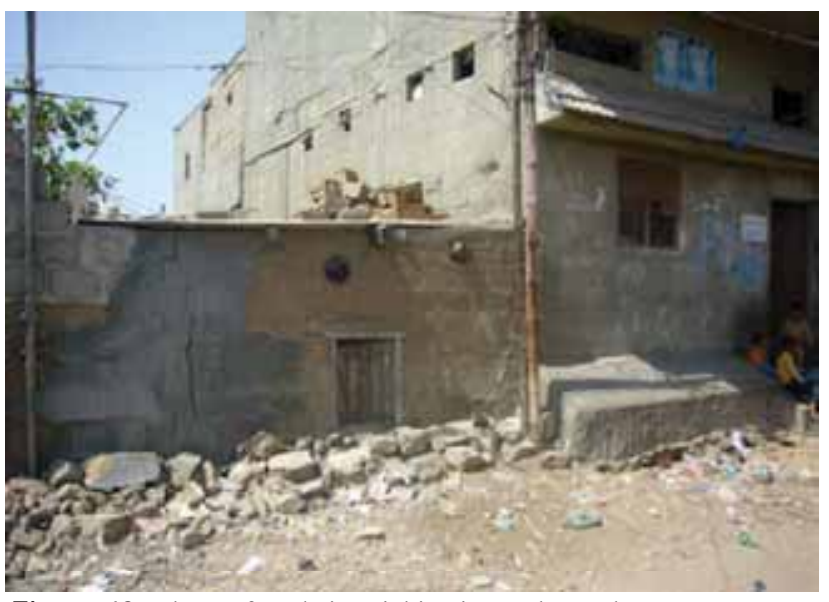

Figures 12: A house foundation sinking in Machar Colony

for incremental construction of the house. As one of the respondents mentioned "Singhar aurtoun ka shauq hae" (Beautification is women's passion).

Besides, women are perceived as good money managers. As Machar Colony is not leased, hence the community is not eligible for bank loans. For construction and for modification of houses women take part in committee system (Beesi system), in which twenty or less people pool money on monthly or fortnightly basis and one of the twenty members gets eligible for the accumulated money on her turn. The monthly contribution of the members varies from anywhere between two to ten thousand Rupees per month per contributor.

\section{Challenges of Built Space}

The sinking of settlement is an issue. As mentioned before, Machar Colony is a reclaimed land from mangroves' marshes and the sea itself. Though people spend quite an amount on soil refilling by purchasing debris and waste, still the soil is not cured properly and as a result one can see houses sinking. The windows of some of the houses have come down to the level of the lane. This is a common site. Every new house construction is one level up as compared to his/her neighbour's house, as a result in monsoons, the aged house get marooned and water stalled (Figure 12).

Moreover, the construction has become expensive as well. In year 2000, an eighty square yard single storied house could be constructed with an investment of Pakistani Rupees one hundred thousand. Now with the rising cost of construction, the cost of construction of the same can go upto Pakistani Rupees five hundred thousand. 


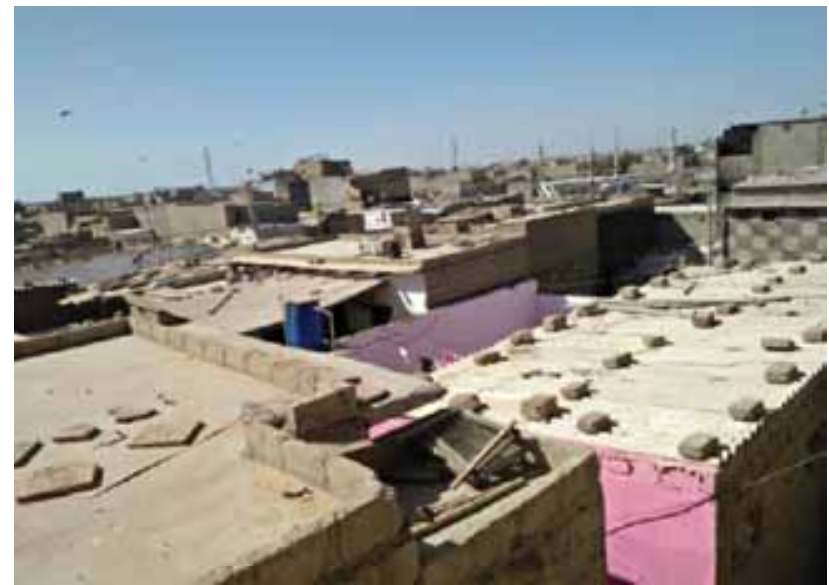

Figures 13: Aerial view of a relatively developed part of Machar Colony

In Machar Colony, because of small plot sizes, parking of vehicles is an issue to reckon with. Though motorbikes are used by majority of the male community members, some do have motor cars as well. During day time, motorbikes are parked in the streets, making them narrower for traffic. The car owners hire spaces away from their house at a cost of Pakistani Rupees thirty per day for parking their vehicles after dusk in a secure area (Figures 13-14).

\section{The Real Estate Market}

Professional real estate agent is a rare commodity in Machar Colony and the real estate market functions through 'acquaintances' and within people of defined communities. Machar Colony has a different mechanism prevailing for the commission on real estate rent. Here, the landlord pays commission to the middleman and that usually does not go beyond one percent of the total monthly rental. In some cases the landlord requests the middleman to reduce the commission further. From the interviews conducted it may be safely concluded that the rental dynamics in Machar Colony is dictated more by social connectivity than the hard core financial considerations.

As mentioned in earlier sections, at the time of this study rumors were strife about the possible land use change of Machar Colony and forcible change of hands. Some of the respondents mentioned that land will go the Malik Riaz of Bahria Town (a private development) with incumbents acting as conduit. A couple of others mentioned that KPT will build infrastructural facilities for the China Pakistan Economic Corridor (CPEC) on the land where Machar Colony exists fight now. These stories had linkages to the reported and alleged displacement of people along the railway tracks which pass from the Colony. As one of the respondents

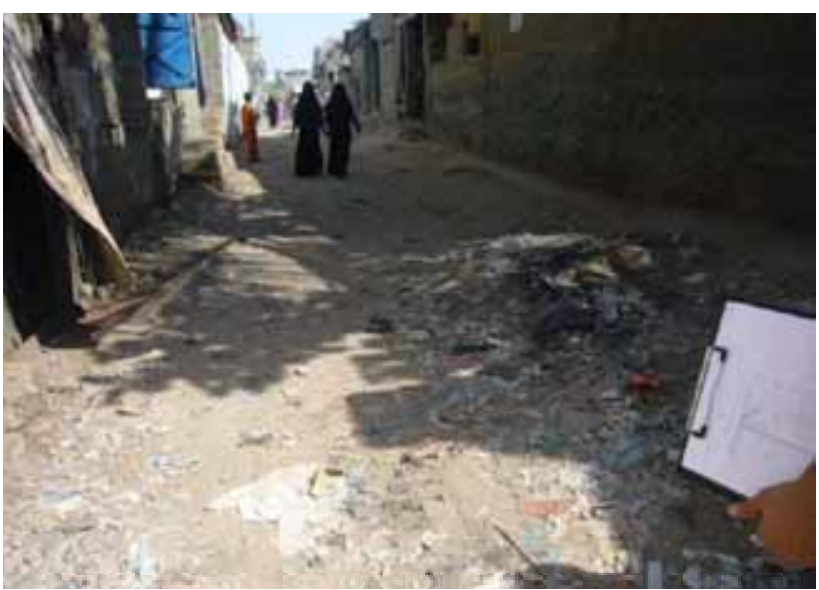

Figures 14: A typical street of Machar Colony

mentioned that "Hum maren ge, magar yahan se utthen ge nahee" (we will die but will not move out from here). As a consequence, the housing prices are stabilized and the boom of real estate prices that happened due to gang war in Lyari is now busted. Earlier a one hundred and twenty square yard house with multi story construction could have gone to Rs. five million Pakistani Rupees. Hence the uncertainty related to development projects has lead to stability in real estate prices.

It is feared that, in the years to come, the population living in Machar Colony will be removed forcefully. Keeping in view the exponential rise of land prices in the city, KPT certainly wish to make the most of it by removing the inhabitants and selling the land to the commercial sector. The sporadic eviction drives by authorities are not uncommon and the fear of the community is not unfounded. That was exhibited in the conducted interviews and triangulated through media reports (Shah, 2017).

The deteriorating law and order situation in the adjourning Lyari neighborhoods has caused an influx of Baloch ethnic population to rent houses in Machar Colony. As many Baloch traditionally are associated with fishing business, the proximity of Machar colony with Fisheries act as a catalyst in pro-displacement decision making process. This coming in of a new ethnicity has a bearing on both the culture and rental business in Machar Colony. The rent for a single room is two thousand Pakistani Rupees per month with one community toilet and a bathing place. Such arrangement is mostly availed by bachelors and not families. Rent for a floor is three thousand Pakistani Rupees per floor with the privacy of a washroom. Usually one floor has two to three rooms on it. 


\section{Gender and Public Space}

The residential facility varies anywhere from forty square yards to one thousand square yards. However, majority of the houses are built on eighty square yards with two to three rooms in a house.

The males use streets, hotels, mosque and shops as places for socialization and entertainment, as most of the hotels have a cable TV or USB facility to show movies. Women use places of work, besides homes, for social interaction with other women.

Women movement is dogged by the wandering youth. The corners of the streets are the hotspots and or at chai khanas (tea serving small hotels), those frequently pass comments on the young girls. In the past (before Karachi Operation 2013) women were abused both physically and sexually.

Fisheries is a blessing for females as it provides job opportunities close to their dwellings, and because of this proximity women have no hesitation in accepting night shifts as well. The number of women earing has increased over time.

Majority of the girls in the area are deprived of educational opportunities because of two reasons: they don't have computerised National identity cards (CNIC) and they don't see any future opportunities after getting educated. Despite these setbacks, it was observed that girls' education is on the rise. This is because of the sporadic occurrence of private schools in the vicinity that are catering to the rising demands of education.

\section{The CNIC and Land Entitlement}

While for Pashtuns and other bonafide citizens of Pakistan lack of provision of civic amenities is the biggest problem, the priority of Bengali community is the recognition of their citizenship by the state institutions: denial of CNICs renders those stateless. People are living there since ages but are called and recognized as Bengali (citizens of former East Pakistan and current Bangladesh) by the state institutions, but they face a serious identity crisis.

This grave issue has a domino effect. For instance police personnel can pick up any boy from anywhere. They do it on a regular basis and later release them by taking any amount from ranging Pakistani Rupees five to ten thousand.
As a result the community lives in perpetual fear. Those Bengali immigrants who entered the country after 1974 are still not entitled to citizenship, but they can get informal temporary registration and permission to work. According to the rules of the defunct The National Alien Registration Authority (NARA), all those illegal immigrants who entered the country after July 10, 2000, have no right to work or do business and are, in fact, they are supposed to be deported (Dharejo, 2010)

As per the law of the land CNIC is an absolute requirement for land entitlement. Those who have CNICs can easily become the land owner irrespective of their share in the purchase or other necessities for inheritance.

\section{The Commercial Spaces}

It was observed in Machar Colony that there is no clear demarcation or segregation of commercial and residential land uses. Small shops are carved out from houses and mosques. J heenga bara and fish drying spaces are located right in the heart of the residential spaces. A typical street, hence could be a combination of shops, tea shops, places of worship small shops, jheenga bara, fish drying godowns and in some instances small cattle farms can be seen on a regular sheet as well.

Commercial spaces are dominated mostly by males, though customers could be of both genders. However, little girls are found in the streets selling homemade food stuff to other children and at times to adults as well. Gender insensitivity could also be observed, as foul language in public spaces is more a norm than exception. This male domination has a bearing on the construction style as well. Unlike designing of houses, women have least say in commercial spaces and hence those places display a blatant gender disparity.

Because of lack of open spaces, children have fewer opportunities for outdoor sports. Moreover because of vehicular traffic (dumpers, water tankers, commercial vehicles and trucks), they are cannot play in adjoining lanes and streets. Number of motorbikes has increased tremendously over time. In the absence of footpaths and encroached streets by commercial ventures walking becomes quite a task. (Figures 15-18). 


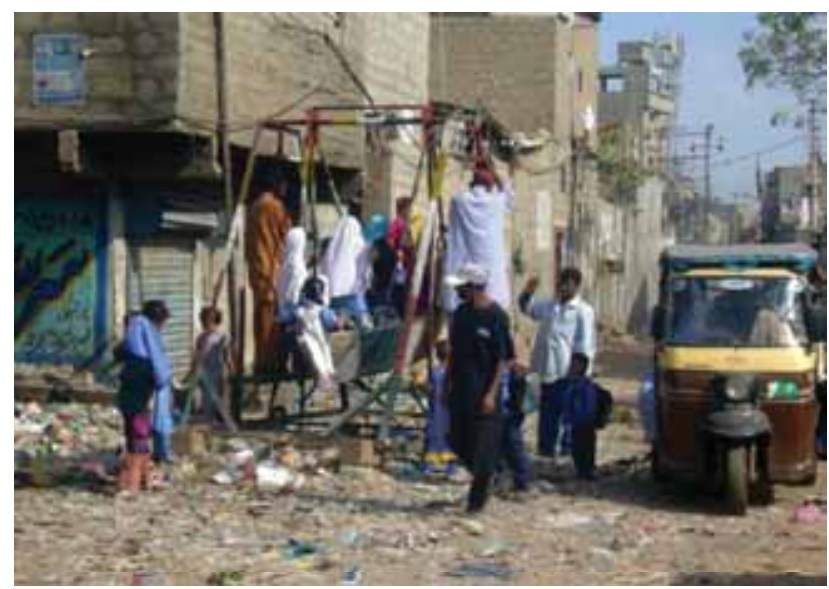

Figures 15: Children playing in the streets in Machar Colony

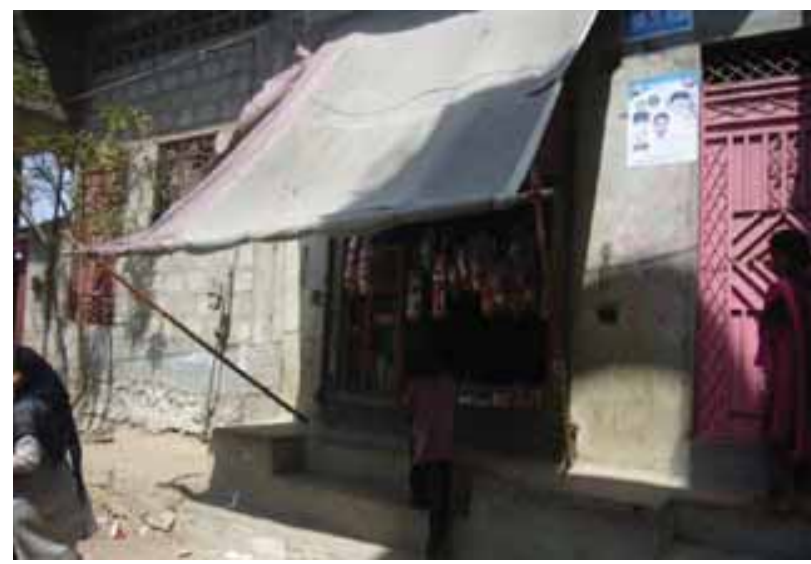

Figures 17: A grocery shop in Machar Colony

Civic Services, Social Dimensions and Impact on LandUse and Housing

\section{Electricity}

After submitting application for a Karachi Electric (KE) meter, it usually takes fifteen days to two months to get the meter installed. The bribe rates could vary from Pakistani Rupees five hundred to five thousand. Once a house gets electric connection, the household gets confidence about the land ownership. Load shedding, irrespective of the weather, is common for two to three hours at a stretch and happens three times in a day. In case of technical fault, maintenance of electric lines (after pole mounted transformer (PMT) is achieved by pooling funds and on self-help basis. Many houses have installed kundas (illegal direct connections) for getting electricity. To penalize the community for nonpayment and perceived threat of electricity, KE is used to switching off electric breaker at the PMT. In such a scenario

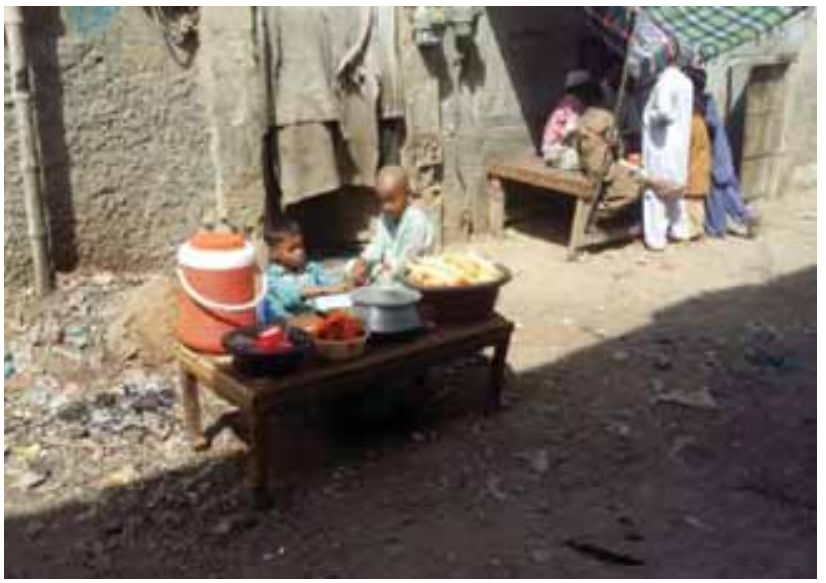

Figures 16: Children selling home cooked snacks in Machar Colony

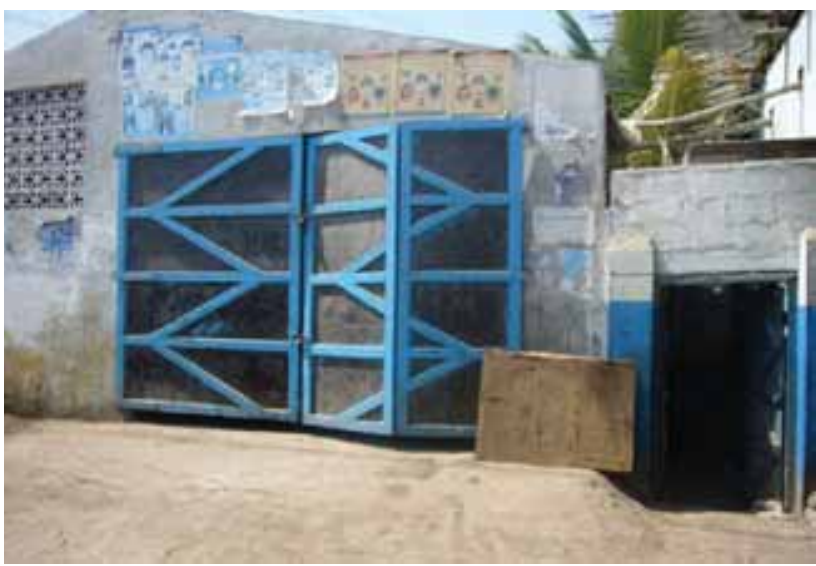

Figures 18: Entrance to the jheenga wara

a Community Based Organization (CBO) called Sher-eBengal plays a role as it collects money from households and gets electricity restored on half of the due payment.

\section{Potable Water}

For Machar Colony dwellers getting potable water is an issue to deal with. People have to purchase potable water and that too is not fit for drinking purposes. Potable water is available through small or big tankers and for other utilities one has to get boring done in the house. The boring goes thirty five to forty feet below the ground and costs Pakistani Rupees twelve to fourteen thousand. Almost every house has dug up for 'boring', but the sub soil water is brackish. So people use brackish water for cleaning and washing, while they have to purchase potable water. The private contractors provide them through tankers, truck and donkey carts. 
The prices for Suzuki water bowser are Pakistani Rupees twelve hundred per bowser and a Shahzore truck costs Pakistani Rupees two thousand per bowser. This browser is usually shared between three to four households and lasts three hundred and twenty days. Majority of the community uses mixed water. The supply of water to bowser is from hydrants located at the Hub River Road and also from Safoora Goth hydrant in District East of Karachi. To make water available for twenty four hours new house constructions have small underground water tanks constructed. Readymade fiber overhead tanks are also installed for overhead water collection.

\section{Sewerage}

Majority of the households rely on pit latrine systems. All the human excreta goes down and when the sea levels are up especially on full moon days, the waste washes away with the tides.

This contributes to the existing elevated water table of the settlement. Water is available at a depth of ten to twelve feet. This in turn contributes to the sinking of the settlement. When the street elevation gets low the community makes it higher by land filling, but the house level cannot be raised. To increase the level of the house a further elevation is required. Therefore the cycle continues.

\section{F uel for Cooking}

Once a person has an electric meter installed by $\mathrm{KE}$ it is then easy to get the gas connection. Two years ago this costed Pakistani Rupees five thousand for a forty square feet pipe to get the gas connection. Now this cost has risen by three folds. Sui Southern Gas Company officials (SSGC) usually roam in the streets and one just has to request them for a connection and rest is taken care of by them. The monthly amount of the gas bill is Pakistani Rupees three hundred to four hundred per month. A wide spread impact of the availability of the gas connection has been that the Pashtun wood sellers (wood was used for coking purpose, method still prevalent in some parts of the settlement) went out of business and had to change their profession to block making. They got support from those who were already in the business.

\section{Health Services}

The provision of health service is mostly in the hands of private practitioners and quacks, where homeopaths are practicing allopathy. The most prevalent health issue is
Hepatitis C, dermal infections, diarrhoea, eye infections, cataract and diabetes in old agers are other prevalent health risks. Birth attendants are not properly trained and they either learn by hit and miss, or claim to have that skill through ancestral lineage. Since the roads are not paved, dust and the accompanying allergies are common. As majority of the population is associated with fishing and allied industry, skin related ailments are an associated professional hazard. Because of poor solid waste management Dengue and Chicken Gonia are frequent epidemics in the area. It was also cited that because of increased human activities and associated waste, pollution has increased over the years. That was also held responsible for the unsatisfactory health situation in the area. To address the health related issues, a considerable number of NGOs have made Machar Colony their abode. They hire residential units on relatively higher rents to open up a clinic. Those NGOs also run awareness campaigns which result in some limited attitudinal change of the community members, regarding health and hygiene, and their method of operation has an impact on gender.

\section{Solid Waste Disposal}

Solid waste is not disposed through an agency driven system. Door to door service of waste collection is provided by young Afghan boys on a monthly payment of Pakistani Rupees fifty by each house in the locality. They collect, sort and dump the rest of the waste across the railway lines. In monsoons, the spread of the solid waste in the lanes and the presence of mud result in accumulated rain water (the rain water usually remains there for two to three months) and stinking sludge that accrues to the disadvantage of the residents and pedestrians with prevalent foul smells. Furthermore, the vacant plots in the area are used to dump wastes, making living conditions difficult for adjoining houses and across small lanes.

\section{Education}

There are two government schools in the area which are located at a considerable distance. Students have to travel a considerable distance, and in some instances, face sexual harassment by socially deviant elements of Machar Colony A considerable number of private indigenous English medium schools also cater to the children of the area. They are usually dark, dingy Dickensian style buildings with no facilities of play grounds or open spaces for physical activity. To tackle this issue, an NGO Imkaan, provides space for physical training, though to a limited number of students. Though there is an increase in educational attainment, but still a lot of children do not attend school. The reasons for parents 
not sending children to school is inflation and associated unaffordability (government schools are far away and this appears as a particular problem for female students). One other reason for not sending children to schools is that fishing is a family enterprise and every member of the household gets involved in this business to maximize earning. It is to be noted that payments are made on per unit or as commonly referred to 'per piece' basis. As discussed above, families with better educational attainment have a different taste for living and decoration of houses. Some very educated families in search of 'gentry', prefer to move out of the fishing business and of the locality as well. Hence education is a means of upward social mobility resulting within city migration as well.

\section{Credit Provides a Reason to Stay}

Grocery is provided on credit by the neighborhood shopkeepers. Men go to the sea for livelihood and women are left behind to take care of the household. The credit basis is by and large extended on ethnicity as Bengali shopkeepers prefer to give credit to their own community, in all probabilities because of location of the shop within community and because of social network. It is interesting to note that the shopkeepers also act as a source of information for the interested tenants, as the community has a daily interaction with shopkeepers for grocery items and other necessities of life.

The monthly salary usually ends by the last week of the month and then onward grocery is procured on credit from the grocery shops in the neighborhood. Here the history, credibility and the pay back capacity of the person who takes the loan are the qualifying factors for credit. A long tenure of living in the neighborhood also helps to establish the required credibility. Hence people are hesitant to leave their neighborhood.

\section{CONCLUSIONS AND RECOMMENDATIONS}

\section{Conclusions}

The above-mentioned discussion brings forth many issues that confronts a resident of Machar Colony starting from the decision to make Machar Colony his/her abode to finding a dwelling for daily living there. Most of these are contextual, portraying specific realities (proximity to Mangrove forests, almost zero ground elevation and being without CNIC) and others are a more specific reflection on how the city is governed and by whom.
In Figure 19, some of the important factors are summarized. It is important to mention that these are extracted from the authors' previous work and the eleven interviews for this study. For more authenticity, the sample needs to be scaled up. Those factors that frequented most of the interviews (between eight and elven interviews) are ranked as high factors, and those factors that were continuously reported in five to seven interviews were ranked as medium and less than five were ranked as low.

Besides the above analysis, the findings from secondary literature and the primary investigation could be summarized as follows:

a) Government owned land is easy to occupy not because of the lack of institutional capacity to protect the land but because of the tactical approvals of respective government officials for monetary interest.

b) The community is compelled to take risk of squatting on government lands because the price of land is high in the centre of the city, and it happens because of the comodification of land and housing. As a result it has become a struggle for the poor to locate themselves in the housing circuit of Karachi.

c) The informal sector provides land for housing and this causes to increase the land value. The market then eyes the value tagged land for high end commercial ventures.

d) Because of the uncertain legal status of both the land and the house, services of low quality are secured by paying high prices.

e) Social bondage solidifies with the presence of a homogenous ethnicity. In rental and ownership transactions that 'knowingness of each other' plays a considerable role for providing guarantees.

f) Public spaces for sports and entertainment (cinemas, parks and playgrounds) are not a priority in informal and indigenous land use plans.

g) Spaces for interaction evolve as the settlement defines its commercial, religious and cultural rituals, with a difference in typology of use for genders and age cohorts.

It is evident from the above-stated theoretical discussion that the current day mode of production of capitalism under the theoretical ambit of Neo-Liberalism has commodified the housing (Youth for Human Rights, 2002). This commodification accrues to the benefit of those who have a substantial purchasing power resulting in marginalizing of a large populace to fringes 


\begin{tabular}{ll}
\hline S. No. & Factors \\
\hline 1. & Comparative Low land cost (because of informality) \\
2. & No commmpulsive building codes \\
3. & Size of the house \\
4. & Easy concersions of residential spaces to commercial ones \\
5. & Land entitlement based secondary document \\
6. & Blocks on loan ny thallewalla \\
7. & Proximity to place of livelihood \\
8. & Neighbourhoods inhabited on ethnicity basis \\
9. & Grocery available on credit \\
10. & In adequate provision of civic services \\
11. & Fears of probable displacement \\
12. & Law and order situation \\
13. & Lack of parks, playground etc \\
\hline
\end{tabular}

Figures 19: Scale of Factors Affecting Housing as Deducted from Interviews by Author

of the city. The poor struggle for shelter and in the process create hope in despair by making houses, organizing lanes, procuring services (both formally and informally) and establishing commercial places of their own and yet face vilification of their neighbourhoods by the elite. Their efforts bring price premium to otherwise neglected land and then state and the market comes in action to make value out of marginality...and the process of marginalization continues.

\subsection{Recommendations}

a) The land ownership issue needs to the clarified between the institutions. Once the management of the land gets clear, it would be easier for the people to lobby for regularisation with political parties and relevant agencies.

b) It is recommended that the citizenship status of Bengali population be articulated in definite terms. It is observed from the interviews that they are not going anywhere. Once this has been established, they need to be supported for entrepreneurship in the fishing sector. c) As suggested by experts for other Katchi Abadis (Ahmed, 2018), a housing needs assessment survey needs to be initiated in Machar Colony.

d. Low cost technologies must be promoted, subsidized and if needed provided through government sponsored micro-finance schemes to make housing affordable for the residents of Machar Colony.

e) To protect the mangroves forest from fading away, a densification plan with the help of local CBOs and NGOs needs to be initiated and popularized.

f) The planners and decision makers of the city need to change their standpoint on informal settlements and any plan for evictions should define the compensation package on the basis of the prevalent market rates and should encompass all aspects of dwelling investments. 


\section{REFERENCES:}

Ahmed, 2018, “Home Sweet home”, viewed 20-08-2017 from https://www.dawn.com/news/1393040/home-sweet-home Ahmed, D. S., 2016, “Informal Land Controls, A Case of Karachi-Pakistan”, Cardiff, Wales: School of Geography and Planning, Cardiff University.

Dharejo, S., 2010, "In search of an Identity", viewed 22-06-18, from taha3.wordpress.com/2010/06/02/ in-search-of-anidentity.

Fegue, C. 2007, "WIT Press", viewed February 04, 2018, from International J ournal of Sustainable Development and Planning, From https://www.witpress.com/elibrary/sdp-volumes/2/4/303

Hasan, A. P., 2017, “Drivers of Climate Vulnerability at Different Scales in Karachi,” Working Paper, p. $104-137$.

Hasan, A., 2011, “Designing Density in Karachi - Alternatives to Apartment Blocks", LSE Cities.

Omenya, A. $2007, \quad$ "Wiredspace” viewed March $07, \quad 2018, \quad$ from http://wiredspace.wits.ac.za/bitstream/handle/10539/2185/Chapter\%202.pdf? sequence=3\&isAllowed=y

Roy, A. 2005, "Urban Informality - Toward an Epistemology of Planning”, J ournal of the American Planning Association, Vol. 71: 2, 148-156.

Siddiqui, T. 2015, “Housing for Poor”, Guest Lecture Series Number 3:7.

Shah, Z., 2017, "30 Houses Razed to the ground in Machar Colony of Karachi”, viewed 22-07-18, from https://www.geo.tv/latest/136891-30-houses-razed-to-the-ground-in-Machar-Colony-of-Karachi.

The News September 07, 2006, “Initiative to promote Machar Art", The New, viewed 22-06-18, from https://www.thenews.com.pk/archive/print/22889-initaitive-to-promote-machar-art

UN - HABITAT, 2015, viewed March 07, 2018, from https://unhabitat.org/wp-content/uploads/2015/04/Habitat-III-IssuePaper-22_Informal-Settlements.pdf

Youth for Human Rights, 2002, “United Nations Universal Declaration of Human Rigth”, viewed 24-03-2017, from http:/www.youthforhumanrights.orglwhat-are-human-rights/universal-declaration-of-human-rights/articles-16-30.html

Zárate, L. 2016, April, "They are Not "Informal Settlements"_-They are Habitats Made by People”, The Nature of Cities, vol 6:182-189. 